\title{
A Comparison of five radiographic systems to D-speed film in the detection of artificial bone lesions
}

David Lloyd Hadley

Virginia Commonwealth University

Follow this and additional works at: https://scholarscompass.vcu.edu/etd

Part of the Endodontics and Endodontology Commons

(C) The Author

\section{Downloaded from}

https://scholarscompass.vcu.edu/etd/1273

This Thesis is brought to you for free and open access by the Graduate School at VCU Scholars Compass. It has been accepted for inclusion in Theses and Dissertations by an authorized administrator of VCU Scholars Compass.

For more information, please contact libcompass@vcu.edu. 
(C) David Lloyd Hadley, 2008

All Rights Reserved 


\section{A COMPARISON OF FIVE RADIOGRAPHIC SYSTEMS TO D-SPEED FILM IN}

\section{THE DETECTION OF ARTIFICIAL BONE LESIONS}

A Thesis submitted in partial fulfillment of the requirements for the degree of Master of Science in Dentistry at Virginia Commonwealth University.

by

DAVID LLOYD HADLEY

DDS, VCU School of Dentistry, 2005

Director: KARAN J. REPLOGLE

INTERIM DIRECTOR, DEPARTMENT OF ENDODONTICS

Virginia Commonwealth University

Richmond, Virginia

June 2008 


\section{Acknowledgement}

The authors appreciate the assistance provided by Dr. Stephen Gudas from the Department of Anatomy and Neurobiology, Virginia Commonwealth University. We are also grateful for the help of Richard Lehew, Gary Dixon, and Jonathon Coudron. 


\section{Table of Contents}

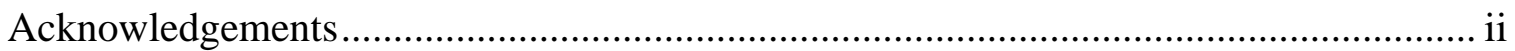

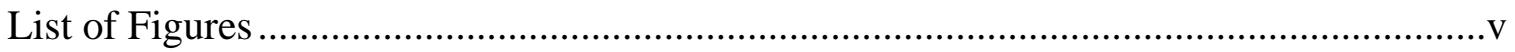

List of Tables .................................................................................................... vi

Chapter

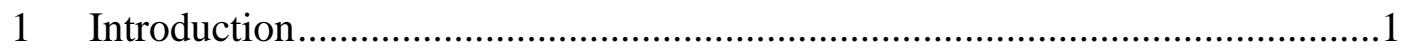

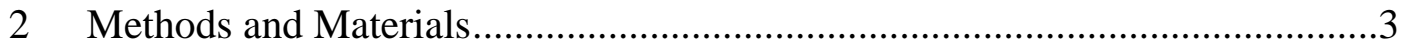

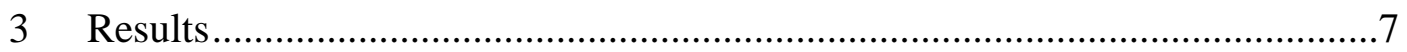

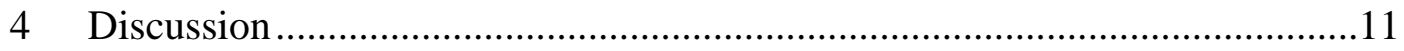

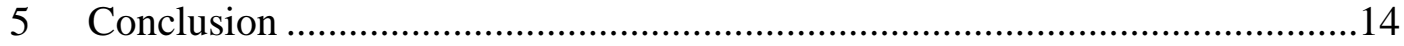

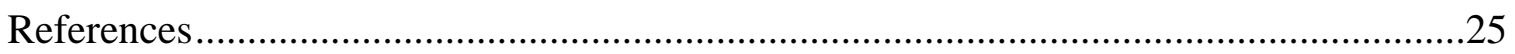




\section{$\underline{\text { List of Figures }}$}

Figure 1: Full length CT scan of mandible sections. .................................................15

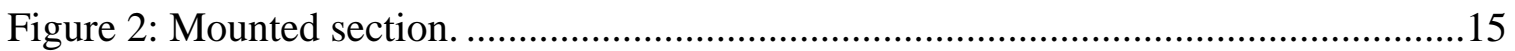

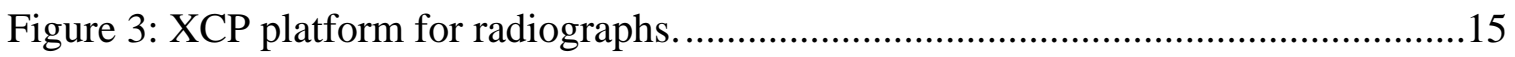

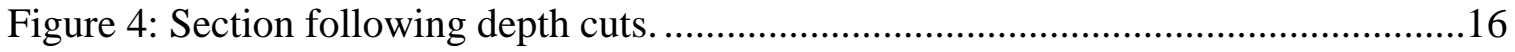

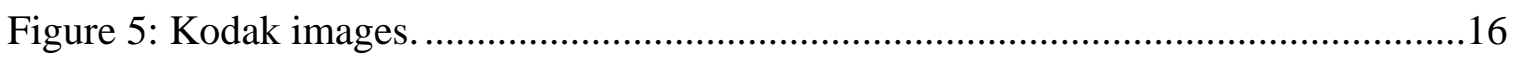

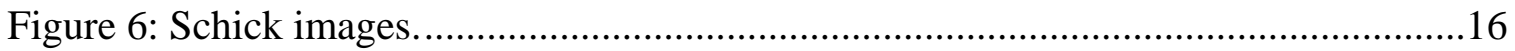

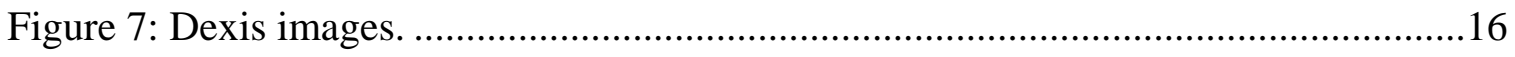

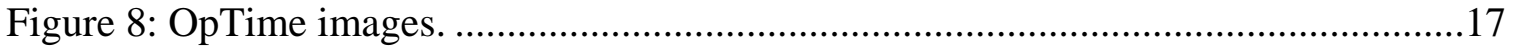

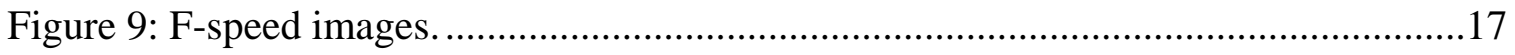

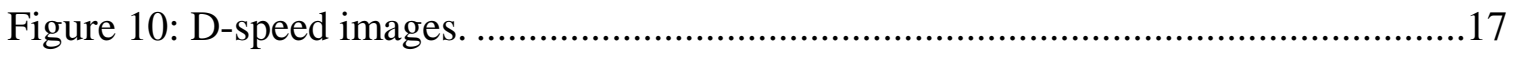

Figure 11: Predicted probability for Kodak system...................................................18

Figure 12: Positive responses for each observer........................................................18

Figure 13: Predicted probability for each imaging system.........................................19

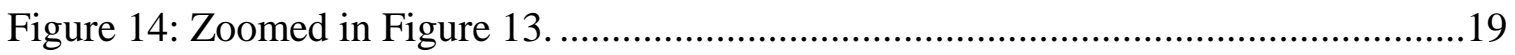




\section{List of Tables}

Table 1: Percentage of cortical bone remaining ...............................................................20

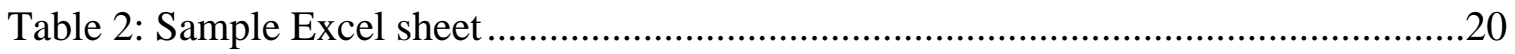

Table 3: Repeated-measures logistic regression results......................................................21

Table 4: Number of lesions detected on each mandible section ..........................................21

Table 5: Number of lesions detected from each observer.................................................21

Table 6: Number of lesions detected for each imaging system .........................................22

Table 7: Predicted probability of lesion detection .............................................................22

Table 8: Predicted probability of lesion detection at mean $\%$ of bone remaining ..............23 


\begin{abstract}
A COMPARISON OF FIVE RADIOGRAPHIC SYSTEMS TO D-SPEED FILM IN THE DETECTION OF ARTIFICIAL BONE LESIONS

By David Lloyd Hadley, DDS
\end{abstract}

A Thesis submitted in partial fulfillment of the requirements for the degree of Master of Science in Dentistry at Virginia Commonwealth University.

Virginia Commonwealth University, 2008

Major Director: Karan J. Replogle

Interim Director, Department of Endodontics

The purpose of this study was to compare three direct digital sensors (Kodak 6100, Schick CDR, and Dexis PerfectSize), a phosphor plate system (OpTime), and F-speed film to standard D-speed film in the detection of artificial bone lesions prepared in mandible bone sections. Multiple artificial bone lesions were prepared at varying depths in the cortical bone. Specimens were imaged with six different radiographic systems. Radiographs were randomly presented to nine different observers. A logistic regression analysis indicated that the ability of the different radiographic systems to detect the bone lesions was significantly different at the mean percentage of cortical bone remaining. The Kodak filtered, Schick filtered, OpTime unfiltered, Schick unfiltered, and Dexis filtered 
images were significantly better at lesion detection compared to D-speed film. Also, all filtered digital images were significantly better at lesion detection than D-speed film. 


\section{\{CHAPTER 1 Introduction\}}

Radiographs are routinely used as part of clinical diagnosis to detect periapical changes. The gold standard for many years in dental radiology has been D-speed film. During the 1980’s and 1990’s, E-speed and F-speed film were introduced by manufacturers as alternatives to reduce radiation exposure to the patient. Over the past ten to fifteen years, digital radiographic systems have been introduced that offer many added benefits, among them a more rapid exposure time and an even greater reduction in radiation exposure (1). Specifically, these digital systems include the direct digital sensors and phosphor plate sensors. Although these digital systems offer advantages, their diagnostic ability to visualize bony changes versus film has been found to be inferior to or equal to standard film in lesion detection.

For example, Kullendorff et al (2) found that conventional film performed slightly better than direct digital radiography in the detection of periapical bone lesions. In another study Wallace et al (3) found that E-speed film displayed the highest sensitivity and specificity for the detection of simulated periapical lesions followed by phosphor plate and direct digital images. Similarly, Friedlander et al (4) concluded that the perceived clarity of a small or large periapical lesion was significantly less on all phosphor plate images compared with conventional films. On the other hand, a number of investigators have concluded there are no significant differences between digital images and conventional film images in the ability to identify periapical bone lesions $(5-8,21)$. Furthermore, some studies have focused on the differences among the digital systems themselves (7, 9). Folk 
et al (9) compared two digital systems, the Schick CDR and Trophy RVGui in their ability to detect bone lesions and concluded that there was no significant difference in the accuracy of detecting artificially prepared periapical lesions between the two direct digital systems.

As computer technology has improved, advances have been made in hardware and software. These advances have affected the capturing capabilities and image resolution of digital devices bringing about a need to examine and compare these changes and analyze their impact clinically. The purpose of this study was to compare three direct digital sensors (Kodak 6100, Schick CDR, and Dexis PerfectSize), a phosphor plate system (OpTime), and F-speed film to standard D-speed film in the detection of artificial bone lesions prepared in mandible bone sections. In addition, filtered and unfiltered images within the three direct digital sensor systems were compared to D-speed film for differences in lesion detection. 


\section{\{CHAPTER 2 Methods and Materials\}}

Seven posterior human mandible sections were collected. No information about the race, age, background, etc., of the cadavers was available. The soft tissue was completely removed. The sections were labeled and stored in 10\% formalin for 3 months. The sections were then stored in a 10:1 water to $5.25 \%$ sodium hypochlorite solution for 2 weeks. Sections were removed from solution and placed in a vented hood for 6 weeks until dry. Each section was then subjected to a full length CT scan to measure the width of the buccal and lingual cortical plates (Figure 1).

All sections were luted onto a plastic base with jet acrylic (Figure 2). An XCP paralleling device was utilized with each mandible section for all radiographs to ensure a reproducible path of the x-ray beam during exposure (Figure 3). An initial bucco-lingual radiograph of each section was taken before any alterations or preparations in the bone were made (Figuress 5a-10a). The Gendex GX770 radiographic unit was preset at $70 \mathrm{KVp}$ $7 \mathrm{~mA}$ for all images. The exposure time was set at Kodak's recommended setting of 0.18 impulses for D-speed film. F-speed film exposure time was set at Kodak’s recommended setting of 0.10 impulses. Exposure time for the OpTime phosphor plate was set at 0.12 impulses. Soredex does not give recommendations for their OpTime plates. They suggest finding a contrast that is acceptable through trial. The Kodak 6100 sensor was set at 0.03 impulses. Kodak recommends a 0.18 impulse setting for $70 \mathrm{kV}$ and $8 \mathrm{~mA}$ and to reduce settings if the images are too dark. All images above 0.03 impulses were too dark for diagnostic purposes in this study. Exposure time for the Dexis PerfectSize sensor was set 
at 0.12 impulses. Dexis recommends between 0.12-0.16 impulses and a reading of 25003500 on their radiation gauge, which is found on their software. The Schick CDR wired sensor was set at 0.03 impulses. Schick recommends between 0.04-0.05 impulses or lower. All impulse settings were determined by starting at the manufacturer recommendations for the mandibular premolar area and by determining the optimum contrast for diagnosis through a pilot study. Traditional films were processed at 81 degrees Fahrenheit in the Air Techniques AT/2000 automatic processor.

Simulated bone lesions were created by removing varying depths of cortical bone using a No. 560 low-speed bur. Rubber stoppers were used to control the depth of the cuts. Single-hole cuts of varying depths were made randomly in the buccal plate in a marked pattern consisting of 3 rows and 4 columns. A negative control was defined in an area of the pattern by a mark corresponding to the width of the No. 560 bur without a cut being made. Sequential depth cuts of cortical bone were then removed in random positions on a prearranged grid. The initial depth cut was $0.25 \mathrm{~mm}$; the second was $0.5 \mathrm{~mm}$; the third was $0.75 \mathrm{~mm}$. Cuts increased in increments of 0.25 millimeters. This continued until 2.0 mm of buccal cortical bone had been removed (Figure 4). A final positive control was made by fully penetrating both cortical plates and the cancellous bone of each section. Sections had varying amounts of cortical bone remaining after preparation of the depth cuts ranging from $93.9 \%$ to $0 \%$ (Table 1). After completion of the depth cuts, a final radiograph was exposed with each digital device and type of film from the buccal direction using the XCP device (Figures 5b-10b). 
Digital radiographs were viewed using manufacturer software with a 15-inch laptop monitor with the resolution set at $1400 \times 1050$ pixels. The images were viewed in a 5 inch by 7 inch desktop widow. Films were viewed on a standard light view box. Images were evaluated by nine different examiners. The nine examiners had from 5-37 years of clinical experience and consisted of four endodontists and five general practitioners. All examiners viewed a PowerPoint tutorial of instructions and sample images from the pilot study before beginning their examination. Each examiner was given the opportunity to locate sample lesions and ask any questions prior to beginning.

Original study images were paired with depth-cut images for comparison and randomly shown to all examiners (Figures 5-10). Nine different varieties of digital images and films were viewed for the seven different mandible sections. These included four nonfiltered digital images (Dexis, Kodak, Optime, and Schick), three filtered images (Dexis, Kodak, and Schick), and two traditional film images (D-speed and F-speed). OpTime images were not filtered for comparison because the CliniView software did not have a filtering tooth. All digital images were viewed using the manufacturers' proprietary software. Software from Dexis and Kodak automatically filter images for viewing after exposure. Schick images are set to be viewed initially as unfiltered images. Images were first viewed by the examiners according to the manufacturers' original image and then filtered or unfiltered to compare the differences in lesion detection. Logos and specific recognizable portions of the software presentation were covered with card stock on the computer screen to reduce any biases toward a specific imaging brand. Traditional films were presented in generic mounts without labels to conceal which film type was being 
viewed. Common landmarks were pointed out to all examiners for all images. Examiners had 30 seconds to locate any new lesions on the altered images. Positive responses were recorded on a prepared template corresponding to the known location of all lesions for a particular sample with its corresponding depth cuts.

Positive and negative responses were then tabulated on an Excel spreadsheet (Table 2). The binary response from the examiners was modeled using repeated-measures logistic regression procedure (GEE method in SAS PROC GENMOD with and exchangeable covariance structure, SAS Version 9.1, Cary NC). The effects in the model were as follows: percentage of bone remaining, mandible sections, observers, systems, and the percent system interaction to allow the relationship between percent and the response to vary depending upon the system (Table 3). 


\section{\{CHAPTER 3 Results\}}

Each of the mandibular sections varied systematically due to the varying amounts of actual cortical bone remaining on each depth cut location (Table 4). For example, for mandible section 1, depth cut 5 (83.3\% bone remaining), five lesions were located out of 81 possible instances ( 9 observers $x$ 9 image systems $=81$ possible instances). Mandible section 1 had the fewest number of lesions detected (21\%), and mandible section 5 had the most number of lesions detected (64\%).

The experimental design allowed for different observers to have different rates of lesion detection. Table 5 shows the number of positive responses for each observer and depth cut. That is, for observer 1, depth cut 2 (which, averaging across all specimens has 92.7\% bone remaining) there were 3 instances where a lesion was observed. Observer 3 had the lowest lesion detection rate (46\%) and observer 4 had the highest lesion detection rate $(63 \%)$.

Specimen, observer, percentage cortical bone remaining, and image system differences were taken into account using a logistic regression model. The model included the four main factors plus an effect that allowed the relationship with percentage cortical bone remaining to be different depending upon the imaging system. The analysis results are shown in Table 3. The results indicate that the probability of a positive response decreased with the percentage of bone remaining (p-value $<.0001$ ) and that each specimen had a systematically different response ( $\mathrm{p}$-value < .0001). As may be seen in the Figure 11, specimen 7 and specimen 1 (the left-most curves) yielded a positive response with the 
smallest percent and specimen 5 yielded a positive response with the largest percent. The logistic regression analysis took these differences into account while testing for the effects of the other factors.

The results in Table 3 also indicated that the observers responses were different (pvalue $=0.0003$ ). As is shown in Figure 12, observer 9 yielded a positive response at the lowest percent and observer 4 yielded a positive response at the highest percent.

These observer and specimen differences were anticipated and were taken into account when comparing the imaging systems. For both the specimen and observer differences, the trend lines were essentially parallel except at the ends of the curves. This indicates that the observer differences did not depend upon the percentage of bone remaining. As the results in Table 3 indicate, the relationship between the percent bone remaining and the probability of lesion detection was different depending upon the imaging system $(\mathrm{p}$-value $=0.0082)$. This interaction test indicated that the differences between imaging systems varied with the percent bone remaining. This can be seen in Figure 13 where the curves are not parallel. Specifically, the vertical separation between the imaging system lines is larger at the $65 \%$ reference line and narrower at the $80 \%$ reference line.

Referring to Figure 13, no visible differences between the different radiographic systems were observed when less that $30 \%$ or more than $80 \%$ of the cortical bone was remaining in the samples. However, differences between the imaging systems were seen by zooming into figure 13 (Figure 14). For instance, with 80 percent of the bone remaining, all of the imaging systems have low probabilities of a lesion detection ranging 
from 0.316 to 0.0383 . With 65 percent of bone remaining, the imaging systems had a higher probability of lesion detection ranging from 0.718 to 0.880 .

Probabiltiy of lesion detection was calculated at the mean percentage (68.7\%) of cortical bone remaining. The Kodak filtered images had the nominally highest probability (0.786) of lesion detection, followed by the Schick filtered images (0.766), OpTime phosphor plate unfiltered images (0.746), Schick unfiltered images (0.738), Dexis filtered images (0.723), Dexis unfiltered images (0.698), Kodak unfiltered images (0.694), F-speed film (0.653), and D-speed film (0.652) (Table 7).

Furthermore, controlling for specimen and observer differences, a logistic regression indicated that, at the mean percent (68.7\%) of cortical bone remaining, there were significant differences between the various radiographic systems $(p$-value $=0.0051$ ) Specifically, a comparison of D-speed film to the other systems revealed that there were significant differences between D-speed film and the Kodak filtered images $(\mathrm{p}$-value $=$ 0.0001), Schick filtered images $(\mathrm{p}$-value $=0.0016)$, OpTime unfiltered images $(\mathrm{p}$-value $=$ 0.0065), Schick unfiltered images ( $p$-value $=0.0271)$, and Dexis filtered images $(p-v a l u e=$ 0.0217). However, there were no statistically significant differences between D-speed film when compared to the Dexis unfiltered images ( $\mathrm{p}$-value $=0.1839$ ), Kodak unfiltered images $(\mathrm{p}$-value $=0.1585)$ and F-speed film $(\mathrm{p}$-value $=0.9753)($ Table 8$)$.

Within the four digital systems in their original software presentation after exposure (ie. Dexis filtered, Kodak filtered, OpTime unfiltered, and Schick unfiltered) there were no significant differences in lesion detection observed (p-values $>0.27$ ). 
A comparison of filtered versus unfiltered images revealed no significant differences in lesion detection between either the Dexis filtered and unfiltered images (pvalue $>0.05$ ) or the Schick filtered and unfiltered images ( $p$-value $>0.05$ ). However, there were significant differences in lesion detection between the Kodak filtered and unfiltered images (p-value 0.0266). 


\section{\{CHAPTER 4 Discussion\}}

A number of previous studies have concluded that D-speed film has performed equal to or better than direct digital devices and phosphor plate systems in bony lesion detection $(2-8,21)$. The probability of lesion detection with images in the digital radiographic systems in the current study was significantly greater than lesion detection with D-speed film. Specifically, the Kodak filtered, Schick filtered, OpTime unfiltered, Schick unfiltered, and Dexis filtered images were significantly better at lesion detection compared to D-speed film. The current results may be due to recent advances in sensor, scanner, and software technology and could account for the differences from previous studies. It is unlikely that experience with digital radiography played a role in the current study. Of the nine examiners that participated in the study, six of them use D-speed and Fspeed film in their daily practices.

It is also unlikely that our study design for artificial bone lesions interfered with the results. Odontogenic lesions normally initiate around a specific tooth and spread from the cancellous to cortical bone as the lesion expands. In our study design artificial lesions were prepared in the outer cortex of cadaver bone at varying depths. Radiographs were then exposed to compare the different radiographic systems. This experimental design is unlike the normal path of lesion progression in the body. However, previous studies have demonstrated that lesions in cancellous bone are often undetected unless a portion of the cortical bone is affected $(12-18,20)$. It has also been demonstrated that the amount of mineralized bone affected is more important than the size of the lesion (10). Furthermore, a lesion often has to cause $30 \%$ to $60 \%$ cortical bone loss to be visualized radiographically 
(11). Therefore, the authors concluded that lesions prepared in the outer cortex would present in a similar manner radiographically to those prepared from the inner cancellous bone extending toward the cortex. This enabled the authors to perform the current study in a practical method with the ability to more precisely measure the amount of bone removed in the preparation of the simulated lesions.

As suspected, there were no significant differences in lesion detection between the F-speed and D-speed films in the current study. Both standard films were almost equal in their ability to detect artificial bone lesions.

A Comparison of the four digital systems in their original software presentation after exposure (ie. Dexis filtered, Kodak filtered, OpTime unfiltered, and Schick unfiltered) failed to demonstrate any significant differences between the four systems. Although claims of software and hardware superiority have been made by manufacturers, the software and hardware differences between these four main systems in their original format after exposure appear to be inconsequential in lesion detection.

However, comparisons of the filtered and unfiltered images in the digital systems revealed differences between the systems. Kodak filtered images had greatest probability of lesion detection while unexpectedly unfiltered images showed no significant differences in lesion detection compared to D-speed film. These differences were significant. A possible explanation for this is the impulse setting in our study differed from Kodak’s recommended setting. Kodak recommends a 0.18 impulse for $70 \mathrm{kV}$ and $8 \mathrm{~mA}$ and to reduce settings if the images are too dark. Our impulse setting was set at 3 because all images above 3 impulses were too dark for diagnostic purposes. This may have affected 
outcomes for this particular sensor. Likewise, the Dexis filtered images were significantly better at lesion detection than D-speed film while unfiltered images showed no significant differences in lesion detection compared to D-speed film. However, these differences were not significant. Both, the Schick filtered and unfiltered images were significantly better at lesion detection when compared to D-speed film. Schick was the only digital system that was significantly better at lesion detection with both filtered and unfiltered images compared to D-speed film. Again, it should be noted that the OpTime phosphor plates were not included in the filtered comparison as there was not a filtering tool in the CliniView software.

The significant differences of this study were limited to the mean percentage of cortical bone remaining due to the complexity of the data collected. Therefore some questions remain. Would there be significant differences between the tested systems at other percentages of cortical bone remaining? Are the differences observed in the current study clinically significant? Also examiners were not allowed to magnify traditional film or enhance digital images beyond the basic filtering capability on each software program. If examiners had been allowed to magnify and manipulate digital images further, this may have improved the ability of lesion detection with the digital systems. Likewise, a magnification of the D-speed and F-speed film images may have also enhanced the ability of the examiner to detect lesions on traditional film. 


\section{\{CHAPTER 5 Conclusion\}}

We concluded that the Kodak filtered, Schick filtered, OpTime unfiltered, Schick unfiltered, and Dexis filtered images were significantly better at lesion detection compared to D-speed film. Also, all filtered digital images were significantly better at lesion detection than D-speed film. Both, the Schick unfiltered and filtered images were significantly better at lesion detection compared to D-speed film. This was not the case for the Kodak unfiltered and Dexis unfiltered images. These images were not significantly different compared to D-speed film. Overall we concluded that digital devices appear to be improving in their ability to detect bone lesions. 


\section{\{Figures\}}

Figure 1: Full length CT scan of mandible sections

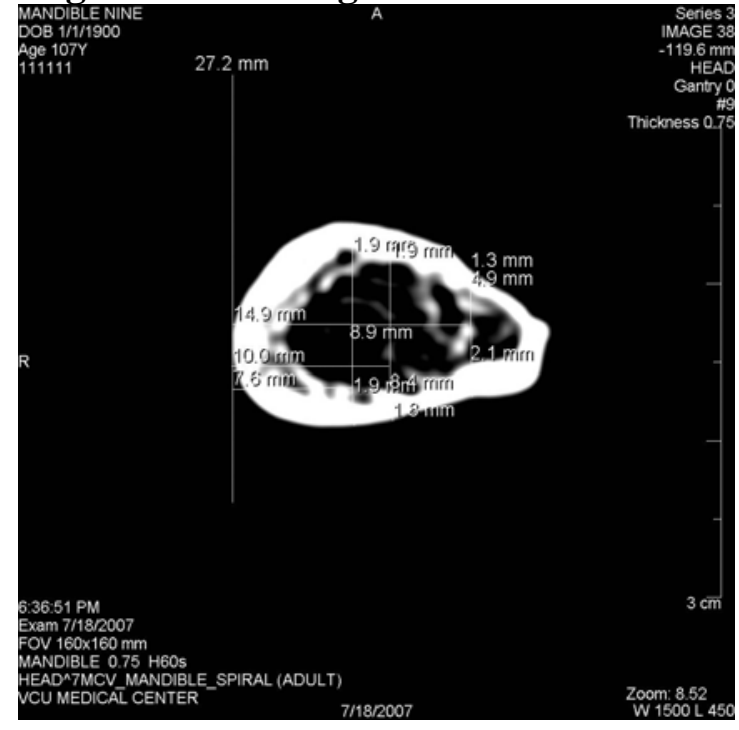

Figure 2: Mounted section

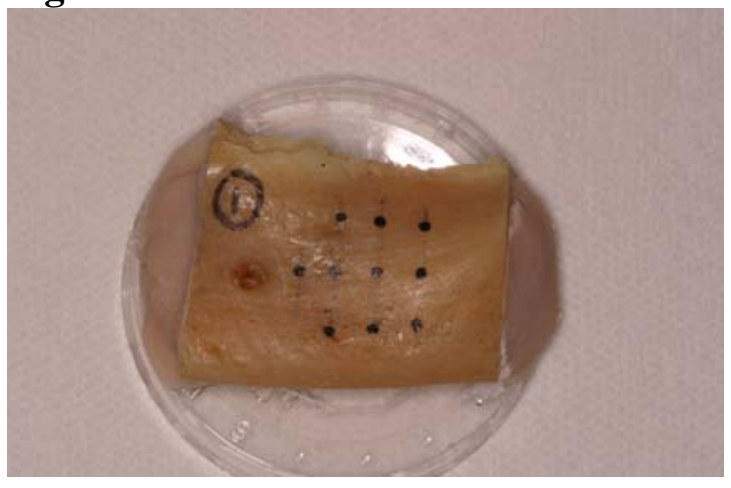

Figure 3: XCP platform for radiographs

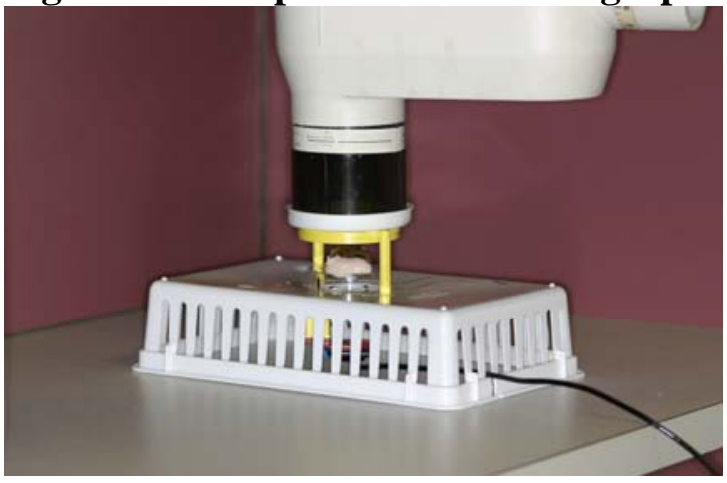


Figure 4: Section following depth cuts

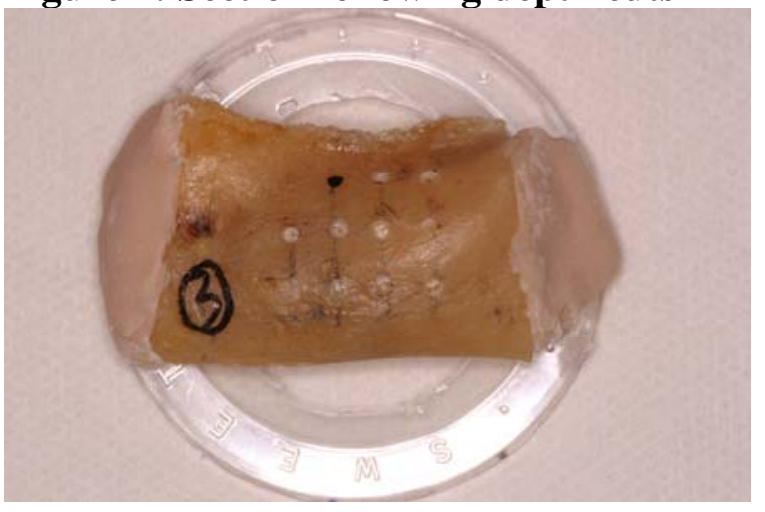

Figure 5a: Kodak

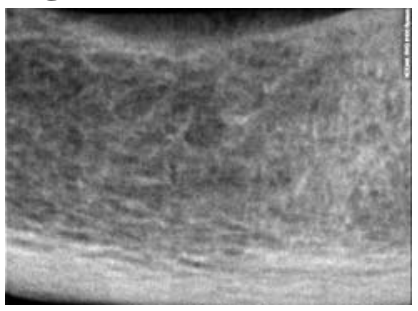

Original

Figure 6a: Schick

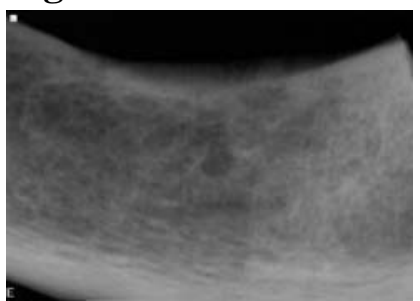

Original

Figure 7a: Dexis

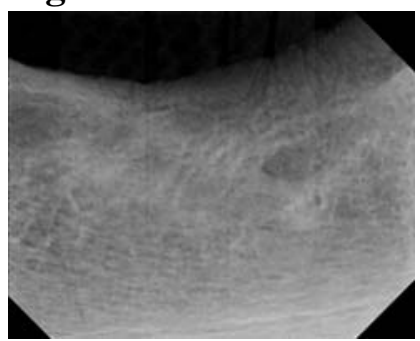

Original
Figure 5b: Kodak

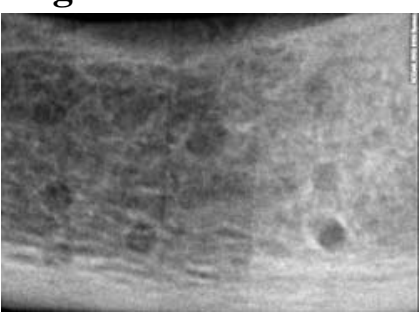

Depth cuts (filtered)

Figure 6b: Schick

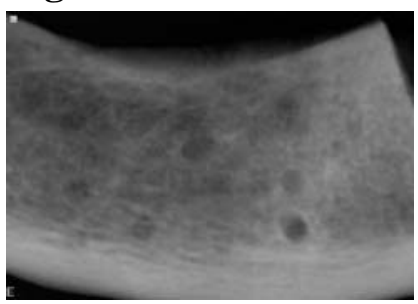

Depth cuts (unfiltered)

Figure 7b: Dexis

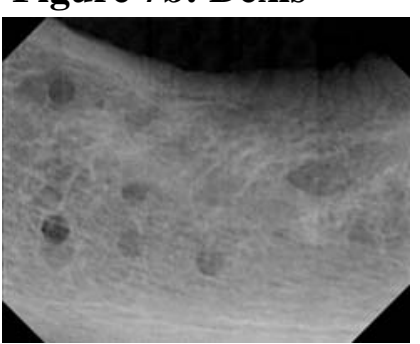

Depth cuts (filtered)
Figure 5c:Kodak

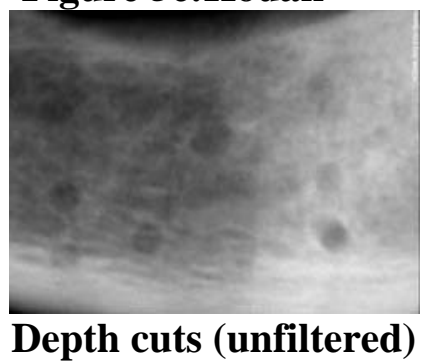

Figure 6c:Schick

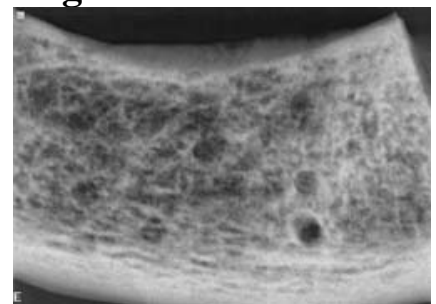

Filtered (filtered)

Figure 7c:Dexis

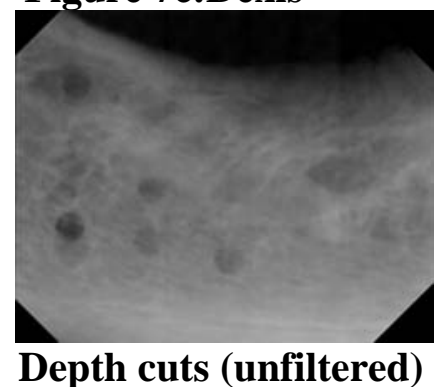


Figure 8a: OpTime

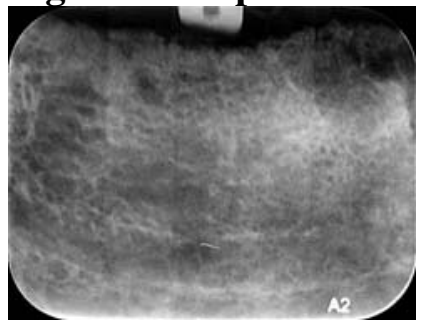

Original
Figure 8b: OpTime

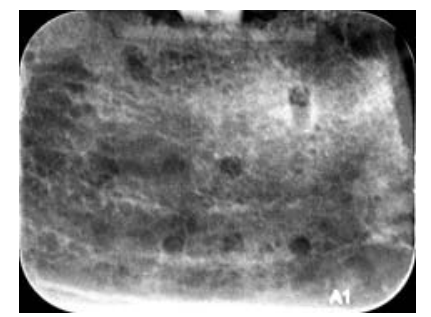

Depth cuts

Figure 9a: F-speed

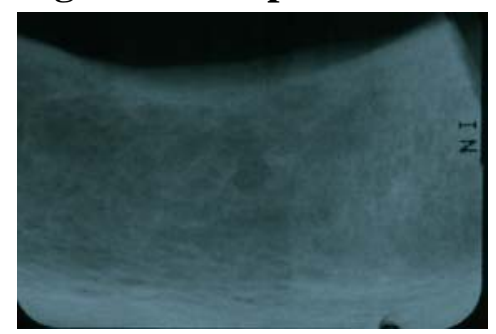

Figure 9b: F-speed

Original (scanned for article) Depth cuts (scanned for article)

Figure 10a: D-speed

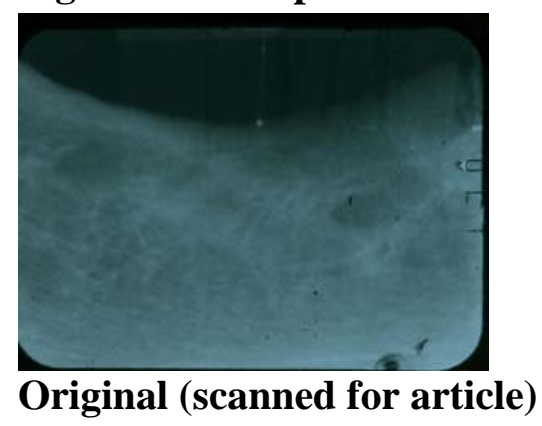

Figure 10b: D-speed

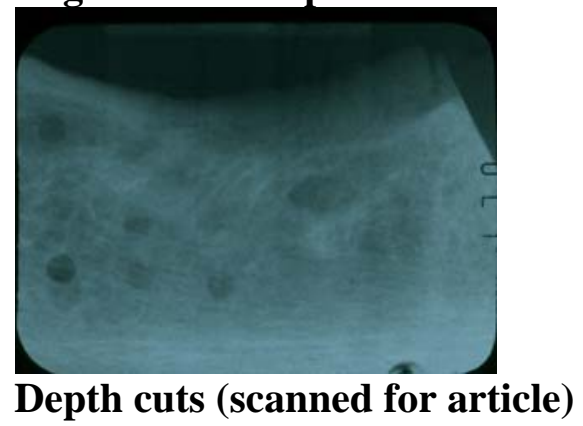


Figure 11: Predicted probability of a positive response for each section, Kodak system only, averaged across all observers

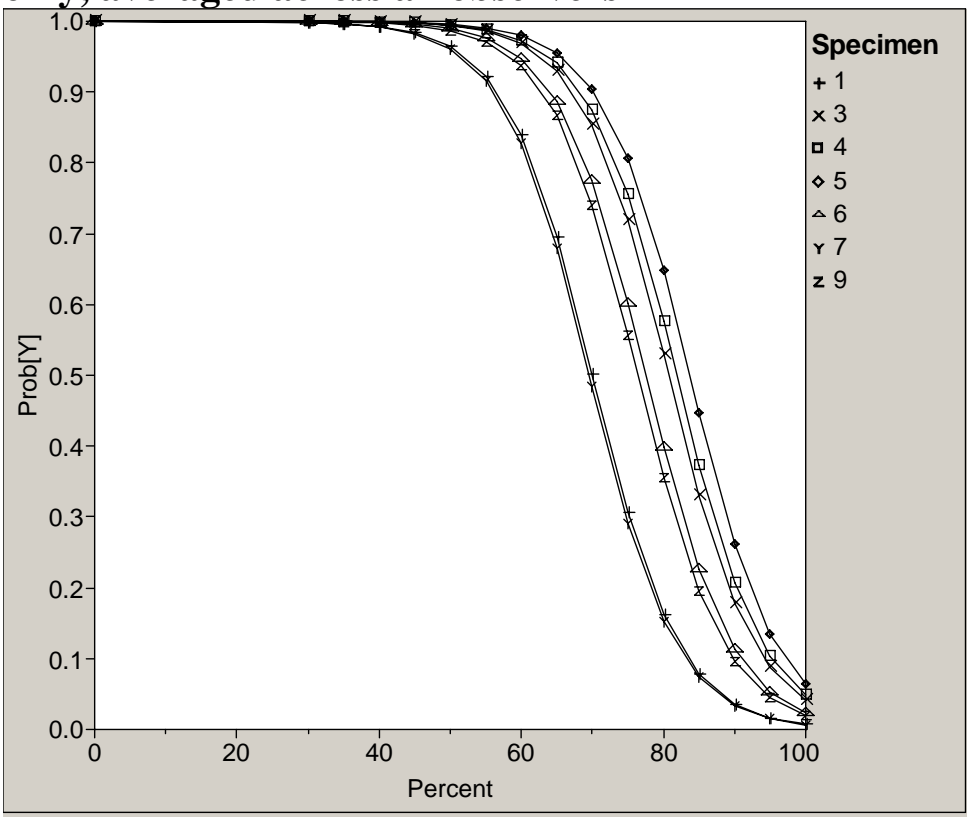

Figure 12: Positive responses for each observer, Kodak system only, averaged across all specimens

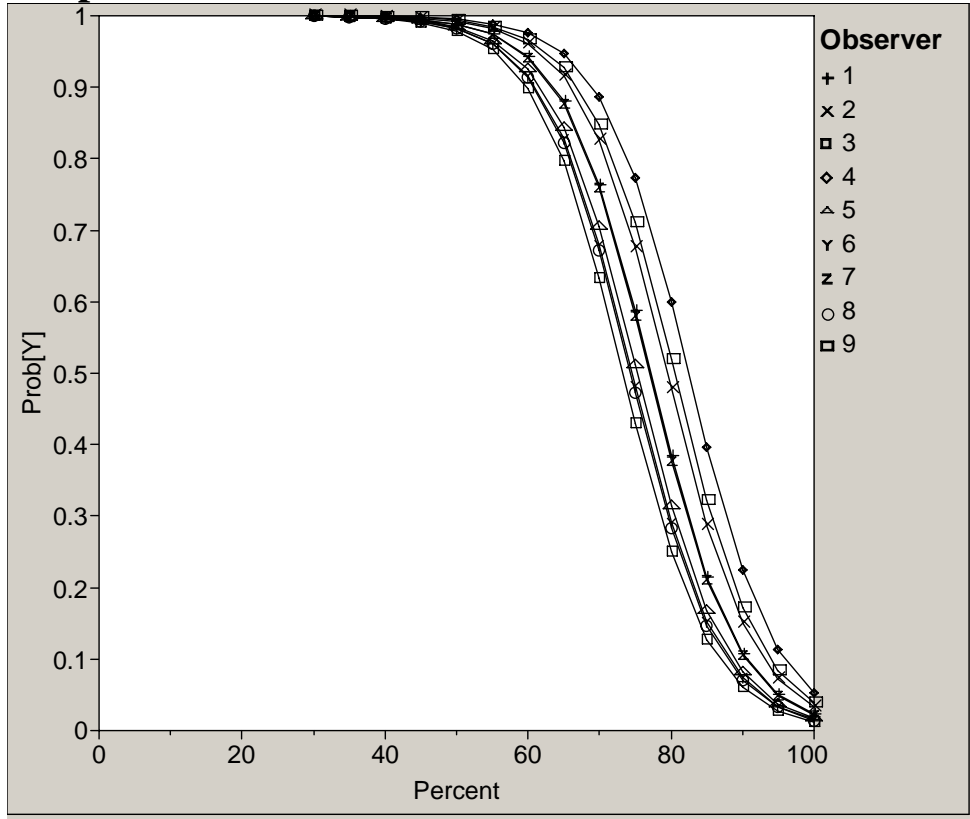


Figure 13: Predicted probability of lesion detection for each imaging system, averaged across all specimens and observers

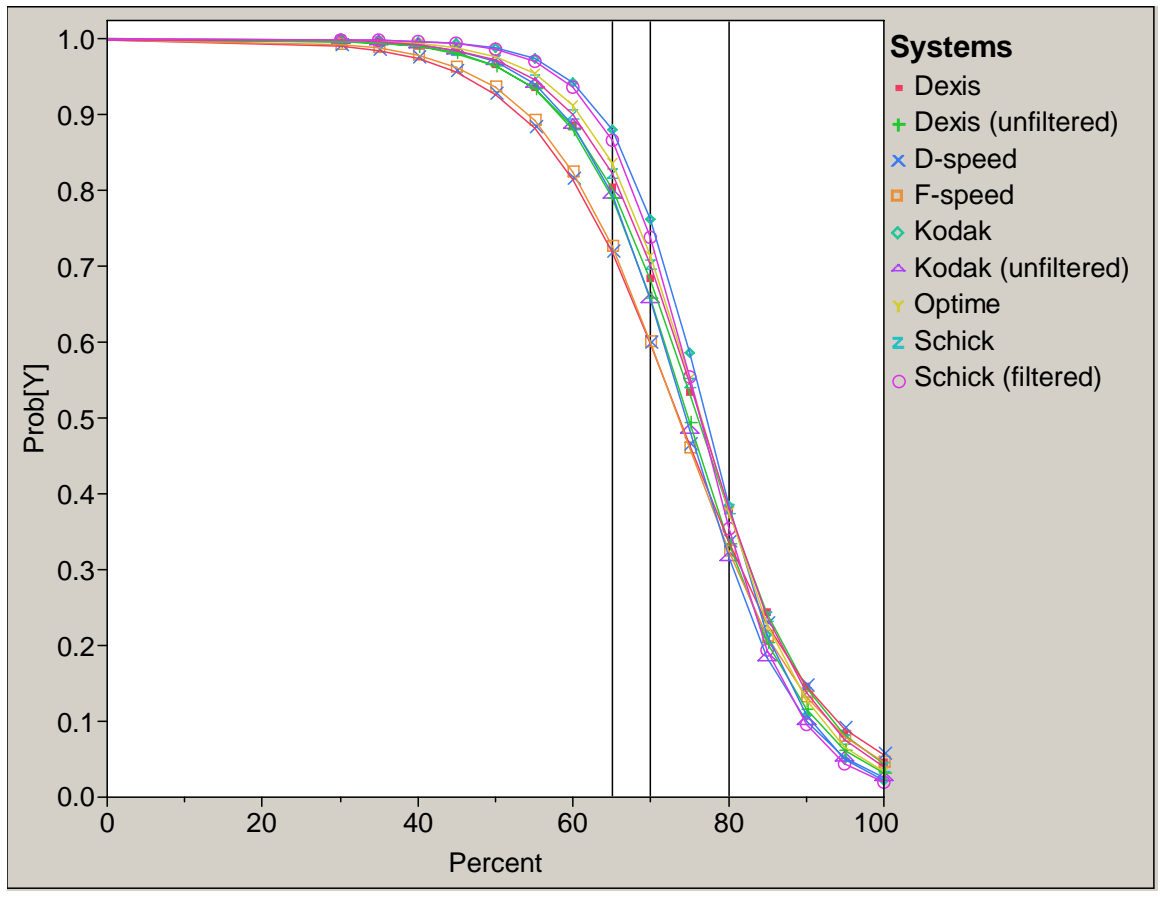

Figure 14: Zoomed in Figure 13

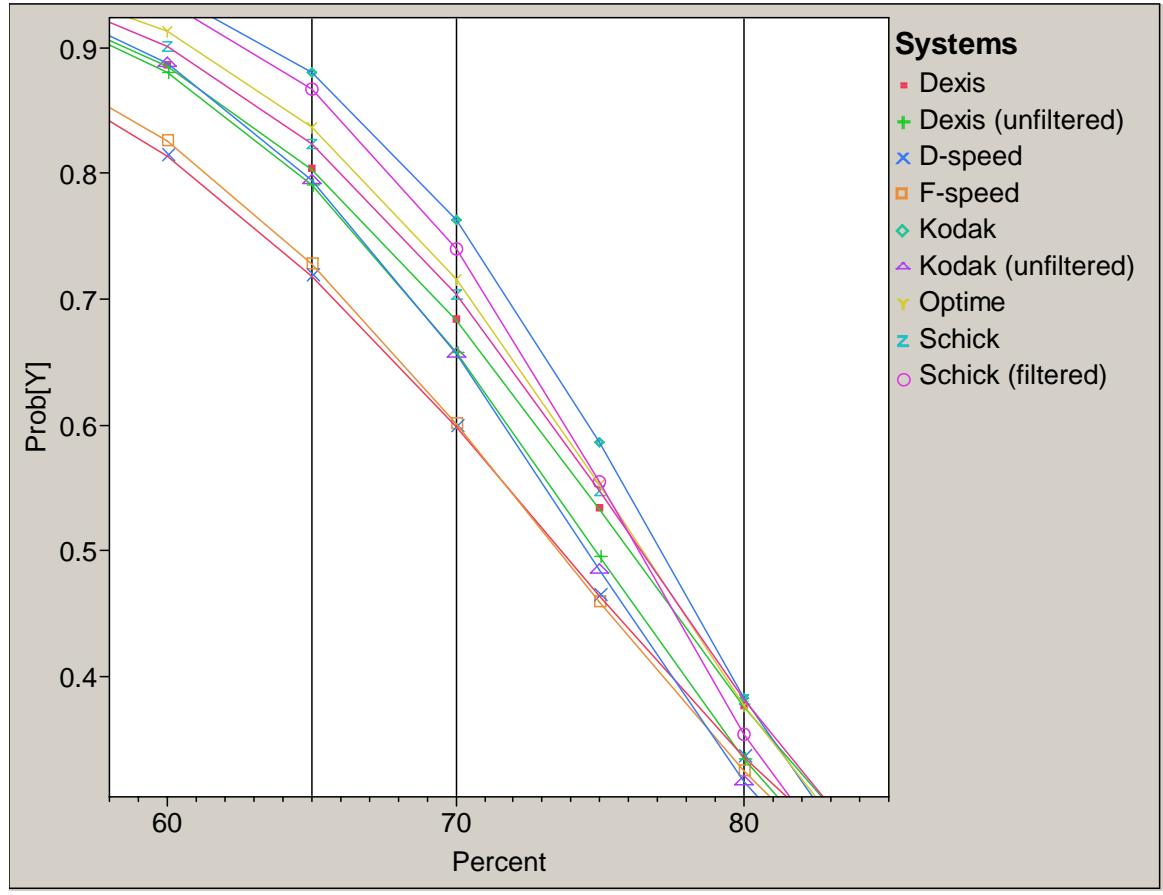




\section{\{Tables\}}

Table 1: Percentage of cortical bone remaining

\begin{tabular}{|c|c|c|c|c|c|c|c|c|}
\hline \multirow[b]{2}{*}{$\begin{array}{c}\text { Penetration } \\
\text { cuts }\end{array}$} & \multicolumn{7}{|c|}{ Sections } & \multirow[b]{2}{*}{ Average } \\
\hline & 1 & 2 & 3 & 4 & 5 & 6 & 7 & \\
\hline $\begin{array}{c}1 \\
\text { (No depth cut) }\end{array}$ & 100.0 & 100.0 & 100.0 & 100.0 & 100.0 & 100.0 & 100.0 & 100.0 \\
\hline 2 & 93.8 & 93.4 & 93.8 & 93.6 & 93.9 & 88.6 & 91.9 & 92.7 \\
\hline 3 & 86.1 & 88.1 & 87.2 & 88.4 & 84.8 & 78.7 & 85.3 & 85.5 \\
\hline 4 & 84.4 & 83.0 & 79.2 & 84.4 & 78.6 & 76.2 & 77.2 & 80.4 \\
\hline 5 & 83.3 & 77.8 & 72.2 & 77.8 & 75.0 & 72.8 & 68.8 & 75.4 \\
\hline 6 & 81.6 & 64.2 & 69.5 & 74.5 & 65.1 & 71.1 & 65.0 & 70.1 \\
\hline 7 & 78.6 & 63.4 & 69.4 & 70.8 & 64.3 & 54.5 & 64.3 & 66.5 \\
\hline 8 & 78.1 & 62.1 & 65.5 & 69.7 & 57.4 & 37.5 & 60.5 & 61.5 \\
\hline 9 & 75.0 & 51.2 & 58.3 & 67.4 & 57.3 & 30.0 & 45.9 & 55.0 \\
\hline $\begin{array}{l}10 \\
\text { (Full buccal } \\
\text { Penetration) }\end{array}$ & 0.0 & 0.0 & 0.0 & 0.0 & 0.0 & 0.0 & 0.0 & 0.0 \\
\hline
\end{tabular}

Table 2: Sample Excel sheet

\begin{tabular}{|c|c|c|c|c|c|c|c|c|c|}
\hline \multirow[b]{2}{*}{$\begin{array}{l}\% \text { Cortical } \\
\text { bone } \\
\text { remaining }\end{array}$} & \multicolumn{9}{|c|}{$\begin{array}{l}\text { Mandibular section } 3 \\
\text { OBSERVER } 9\end{array}$} \\
\hline & $\begin{array}{l}\text { KODAK* } \\
\text { (filtered) }\end{array}$ & $\begin{array}{l}\text { DEXIS* } \\
\text { (filtered) }\end{array}$ & $\begin{array}{l}\text { SCHICK* } \\
\text { (unfiltered) }\end{array}$ & $\begin{array}{l}\text { OPTIME* } \\
\text { (unfiltered) }\end{array}$ & $\begin{array}{l}\text { F- } \\
\text { SPEED } \\
\end{array}$ & $\begin{array}{l}\text { D- } \\
\text { SPEED } \\
\end{array}$ & $\begin{array}{l}\text { KODAK } \\
\text { (unfiltered) }\end{array}$ & $\begin{array}{l}\text { DEXIS } \\
\text { (unfiltered) }\end{array}$ & $\begin{array}{l}\text { SCHICK } \\
\text { (filtered) } \\
\end{array}$ \\
\hline $100.0 \%$ & - & - & - & - & - & - & - & - & - \\
\hline $93.8 \%$ & - & - & - & - & - & - & - & - & - \\
\hline $87.2 \%$ & - & - & - & - & - & - & - & - & - \\
\hline $79.2 \%$ & + & + & + & + & + & - & - & + & - \\
\hline $72.2 \%$ & + & + & + & + & + & + & + & + & + \\
\hline $69.5 \%$ & + & + & + & + & + & + & + & + & + \\
\hline $69.4 \%$ & + & + & + & + & + & + & + & + & + \\
\hline $65.5 \%$ & + & + & + & + & + & + & + & + & + \\
\hline $\begin{array}{r}58.3 \% \\
\text { No cortical }\end{array}$ & + & + & + & + & + & + & + & + & + \\
\hline & + & + & + & + & + & + & + & + & + \\
\hline \# FALSE + & 0 & 0 & 0 & 0 & 0 & 0 & 0 & 0 & 0 \\
\hline
\end{tabular}

(-) no lesion detected

$(+)$ lesion detected

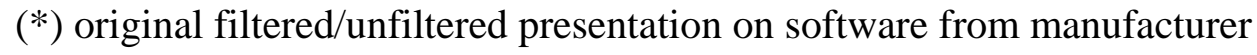


Table 3: Repeated-measures logistic regression results

\begin{tabular}{|lrrr|}
\hline Source & df & $\begin{array}{r}\text { Chi- } \\
\text { Square }\end{array}$ & $\begin{array}{r}\text { p- } \\
\text { value }\end{array}$ \\
\hline Percent & 1 & 204.71 & $<.0001$ \\
Mandible & & & \\
Section & 6 & 86.01 & $<.0001$ \\
Observer & 8 & 29.26 & 0.0003 \\
System & 8 & 21.88 & 0.0051 \\
Percent*System & 8 & 20.64 & 0.0082 \\
\hline
\end{tabular}

Table 4: Number of lesions detected (out of 81) for each depth cut on each mandible section

\begin{tabular}{|rrrrrrrr|}
\hline $\begin{array}{r}\text { Depth } \\
\text { cuts }\end{array}$ & $\mathbf{1}$ & $\mathbf{3}$ & $\mathbf{4}$ & $\mathbf{5}$ & $\mathbf{6}$ & $\mathbf{7}$ & $\mathbf{9}$ \\
\hline $\mathbf{1}$ & 0 & 0 & 0 & 0 & 0 & 0 & 0 \\
$\mathbf{2}$ & 0 & 2 & 0 & 16 & 1 & 1 & 1 \\
$\mathbf{3}$ & 0 & 20 & 2 & 37 & 6 & 52 & 3 \\
$\mathbf{4}$ & 0 & 25 & 31 & 39 & 54 & 52 & 59 \\
$\mathbf{5}$ & 5 & 60 & 81 & 6 & 71 & 23 & 18 \\
$\mathbf{6}$ & 3 & 77 & 81 & 80 & 31 & 49 & 81 \\
$\mathbf{7}$ & 1 & 81 & 79 & 81 & 77 & 12 & 68 \\
$\mathbf{8}$ & 39 & 69 & 81 & 78 & 76 & 46 & 81 \\
$\mathbf{9}$ & 41 & 81 & 80 & 81 & 75 & 81 & 80 \\
$\mathbf{1 0}$ & 80 & 79 & 81 & 81 & 77 & 81 & 81 \\
\hline
\end{tabular}

Table 5: Number of lesions detected (out of 63) for each depth cut from each observer

\begin{tabular}{|rrrrrrrrrr|}
\hline $\begin{array}{l}\text { Depth } \\
\text { Cut }\end{array}$ & $\mathbf{1}$ & $\mathbf{2}$ & $\mathbf{3}$ & $\mathbf{4}$ & $\mathbf{5}$ & $\mathbf{6}$ & $\mathbf{7}$ & $\mathbf{8}$ & $\mathbf{9}$ \\
\hline 1 & 0 & 0 & 0 & 0 & 0 & 0 & 0 & 0 & 0 \\
2 & 3 & 6 & 0 & 5 & 2 & 1 & 1 & 0 & 3 \\
3 & 10 & 13 & 8 & 29 & 15 & 7 & 10 & 11 & 17 \\
4 & 35 & 37 & 16 & 44 & 21 & 20 & 29 & 21 & 37 \\
5 & 31 & 28 & 25 & 42 & 21 & 24 & 30 & 25 & 38 \\
6 & 45 & 51 & 38 & 49 & 41 & 38 & 48 & 42 & 50 \\
7 & 45 & 44 & 45 & 46 & 44 & 46 & 42 & 42 & 45 \\
8 & 50 & 59 & 44 & 60 & 51 & 49 & 52 & 45 & 60 \\
9 & 53 & 63 & 52 & 61 & 56 & 58 & 58 & 56 & 62 \\
10 & 63 & 62 & 62 & 63 & 62 & 62 & 63 & 60 & 63 \\
\hline
\end{tabular}


Table 6: Number of lesions detected (out of 63) for each depth cut and imaging system

\begin{tabular}{|c|c|c|c|c|c|c|c|c|c|}
\hline \multirow[b]{2}{*}{$\begin{array}{l}\text { Depth } \\
\text { Cut }\end{array}$} & \multicolumn{9}{|c|}{ Systems } \\
\hline & $\begin{array}{c}\text { Dexis* } \\
\text { (filtered) }\end{array}$ & $\begin{array}{c}\text { Dexis } \\
\text { (unfiltered) }\end{array}$ & $\begin{array}{c}\text { D- } \\
\text { speed }\end{array}$ & $\begin{array}{c}\text { F- } \\
\text { speed }\end{array}$ & $\begin{array}{c}\text { Kodak }^{*} \\
\text { (filtered) }\end{array}$ & $\begin{array}{c}\text { Kodak } \\
\text { (unfiltered) }\end{array}$ & $\begin{array}{c}\text { Optime }^{*} \\
\text { (unfiltered) }\end{array}$ & $\begin{array}{c}\text { Schick } \\
\text { (unfiltered) }\end{array}$ & $\begin{array}{c}\text { Schick } \\
\text { (filtered) }\end{array}$ \\
\hline 1 & 0 & 0 & 0 & 0 & 0 & 0 & 0 & 0 & 0 \\
\hline 2 & 1 & 0 & 2 & 4 & 2 & 3 & 2 & 5 & 2 \\
\hline 3 & 17 & 10 & 14 & 9 & 14 & 11 & 12 & 18 & 15 \\
\hline 4 & 34 & 29 & 29 & 29 & 36 & 28 & 31 & 23 & 21 \\
\hline 5 & 32 & 27 & 23 & 25 & 34 & 26 & 30 & 32 & 35 \\
\hline 6 & 41 & 46 & 45 & 40 & 47 & 46 & 49 & 43 & 45 \\
\hline 7 & 45 & 46 & 40 & 42 & 48 & 40 & 42 & 48 & 48 \\
\hline 8 & 52 & 52 & 49 & 49 & 50 & 52 & 55 & 56 & 55 \\
\hline 9 & 56 & 58 & 59 & 59 & 55 & 57 & 60 & 58 & 57 \\
\hline 10 & 63 & 61 & 61 & 63 & 63 & 62 & 63 & 61 & 63 \\
\hline
\end{tabular}

(*) original filtered/unfiltered presentation on software from manufacturer

Table 7: Predicted probability of a lesion detection at varying amounts of cortical bone percents remaining

\begin{tabular}{|l|rrrrr|}
\cline { 3 - 6 } \multicolumn{1}{c|}{} & \multicolumn{5}{c}{ Percentage Cortical Bone Remaining } \\
\cline { 2 - 5 } Systems & $\mathbf{3 0}$ & $\mathbf{6 5}$ & $\mathbf{6 8 . 7}$ & $\mathbf{7 5}$ & $\mathbf{8 0}$ \\
\hline $\begin{array}{l}\text { Kodak* } \\
\text { (filtered) }\end{array}$ & 0.999 & 0.880 & 0.786 & 0.586 & 0.383 \\
$\begin{array}{l}\text { Schick } \\
\text { (filtered) }\end{array}$ & 0.999 & 0.866 & 0.766 & 0.555 & 0.354 \\
$\begin{array}{l}\text { OpTime* } \\
\text { (unfiltered) }\end{array}$ & 0.998 & 0.836 & 0.746 & 0.552 & 0.377 \\
$\begin{array}{l}\text { Schick* } \\
\text { (unfiltered) }\end{array}$ & 0.998 & 0.823 & 0.738 & 0.547 & 0.381 \\
$\begin{array}{l}\text { Dexis* } \\
\text { (filtered) }\end{array}$ & 0.997 & 0.803 & 0.723 & 0.533 & 0.376 \\
$\begin{array}{l}\text { Dexis } \\
\text { (unfiltered) }\end{array}$ & 0.997 & 0.790 & 0.698 & 0.495 & 0.334 \\
$\begin{array}{l}\text { Kodak } \\
\text { (unfiltered) }\end{array}$ & 0.998 & 0.795 & 0.694 & 0.484 & 0.316 \\
$\begin{array}{l}\text { F-speed } \\
\text { D-speed }\end{array}$ & 0.993 & 0.728 & 0.653 & 0.460 & 0.324 \\
\hline
\end{tabular}

$\left(^{*}\right)$ original filtered/unfiltered presentation on software from manufacturer 
Table 8: Predicted probability of lesion detection at the mean percentage bone loss (68.7\%)

\begin{tabular}{|lll|}
\hline Predicted & p-value & System \\
\hline 0.786 & 0.0001 & Kodak* (filtered) \\
0.766 & 0.0016 & Schick (filtered) \\
0.746 & 0.0065 & OpTime* (unfiltered) \\
0.738 & 0.0271 & Schick* (unfiltered) \\
0.723 & 0.0217 & DEXIS* (filtered) \\
0.698 & 0.1839 & DEXIS (unfiltered) \\
0.694 & 0.1585 & Kodak (unfiltered) \\
0.653 & 0.9753 & F-speed \\
0.652 & & D-speed \\
\hline
\end{tabular}

The predicted values are the probability of a positive response at $68.7 \%$ bone remaining. The p-value is the comparison of each imaging system with D-speed.

(*) original filtered/unfiltered presentation on software from manufacturer 


\section{Literature Cited}




\section{Literature Cited}

1. Soh G, Loh FC, Chong YH. Radiation dosage of a dental imaging system. Quintessence Int. 1993;24(3):189-91.

2. Kullendorff B, Petersson K, Rohlin M. Direct digital radiography for the detection of periapical bone lesions: a clinical study. Endod Dent Traumatol 1997;13:183-9.

3. Wallace JA, Nair MK, Colaco MF, Kapa SF. A comparative evaluation of the diagnostic efficacy of film and digital sensors for the detection of simulated periapical lesions. Oral Surg Oral Med Oral Path Oral Radiol Endod 2001;91(1):93-7

4. Friedlander LT, Love RM, Chandler NP. A comparison of phosphor-plate digital images with conventional radiographs for the perceived clarity of fine endodontic files and periapical lesions. Oral Surg Oral Med Oral Path Oral Radiol End 2002;93(3):321-7.

5. Barbat J, Messer HH. Detection of artificial periapical lesions using direct digital and conventional radiography. J Endod 1998;24(12):837-42.

6. MistakWest EJ, Loushine R, Primack P, West L, Runyan D. Interpretation of periapical lesions comparing conventional, direct digital, and telephonically transmitted radiographic images. J Endod 1998;24(4):262-6.

7. Paurazas, SB, Geist JR, Pink FE, Hoen, MM, Steinman HR. Comparison of diagnostic accuracy of digital imaging by using CCD and CMOS-APS sensors with E-speed film in the detection of periapical bony lesions. Oral Surg Oral Med Oral Path Oral Radiol Endod 2000;89(3):356-62.

8. Stavropoulos A, Wenzel A. Accuracy of cone beam dental CT, intraoral digital and conventional film radiography for the detection of periapical lesions. An ex vivo study in pig jaws. Clin Oral Investig 2007;11(1):101-6.

9. Folk RB, Thorpe JR, McClanahan SB, Johnson JD, Strother JM. Comparison of two different direct digital radiographic systems for the ability to detect artificially prepared periapical lesions. J Endod 2005;31(4):304-6.

10. Bender IB. Factors influencing the radiographic appearance of bony lesions. JOE 1982; 8:4.

11. Razmus TF. Caries, periodontal disease, and periapical changes. Dental Clin North Am 1994; 38: 13-31. 
12. Bender IB, Seltzer S. Roentgenographic and direct observation of experimental lesions in bone. JADA 1961; 62: 152.

13. Ramadam AE, Mitchell DF. A roentgenographic study of experimental bone destruction. Oral Surgery 1962; 15:934.

14. Regan JE, Mitchell DF. Evaluation of periapical radiolucencies found in cadavers. JADA 1963; 66:529.

15. Wengraf A. Radiographically occult bone cavities. Br Dent J 1964; 117:532.

16. Pauls V, Trott JR. A radiological study of experimentally produced lesions in bone. Dent Practit 1966; 16:254.

17. Schwartz SF, Foster JK, Jr. Roentgenographic interpretation of experimentally produced bony lesions. Oral Surg 1971; 32:606.

18, Ardran GM. Bone destruction not demonstrable by radiography. Br J Radiol 1951; 24:107.

19. Khocht A, Janal M, Harasty L, Chang KM. Comparisons of direct digital and conventional intraoral radiographs in detecting alveolar bone loss. J Am Dental Assoc 2003; 134(11):1468-75.

20. Bianchi SD, Roccuzzo M, Cappello N, Libero A, Rendine S. Radiolocial visibility of small artificial periapical bone lesions. Dentomaxillofac Radiol 1991; 20(1):35-9.

21. Fürkart AJ, Dove SB, McDavid WD, Nummikoski P, Matteson S. Direct digital radiography for the detection of periodontal bone lesions. Oral Surg Oral Med Oral Path 1992; 74(5): 652-60. 


\section{VITA}

David Lloyd Hadley was born January 26, 1976 in Ogden, Utah to Stephen and Anne Hadley. He is a United States citizen. He attended Weber State University and graduated with a degree in Zoology and a minor in Chemistry in 2001. He then attended Virginia Commonwealth School of Dentistry and graduated Magna Cum Laude with a Doctor of Dental Surgery in 2005. David also completed a one-year general practice residency at Palmetto Health Richland in Columbia, South Carolina from 2005-2006. He will graduate from Virginia Commonwealth School of Dentistry with a certificate in endodontics and a Masters of Science in Dentistry in June 2008. 